Research Article

\title{
Identification of Urinary Biomarkers for Exercise-Induced Immunosuppression by iTRAQ Proteomics
}

\author{
Guoqin Xu (D), ${ }^{1}$ Wentao Lin, ${ }^{1}$ Andrew J McAinch, ${ }^{2,3}$ Xu Yan, ${ }^{2,3}$ and Xiquan Weng ${ }^{1}{ }^{1}$ \\ ${ }^{1}$ Department of Sports and Health, Guangzhou Sport University, Guangzhou 510500, China \\ ${ }^{2}$ Institute for Health and Sport, Victoria University, Melbourne 8001, Australia \\ ${ }^{3}$ Australian Institute for Musculoskeletal Science (AIMSS), Melbourne 3021, Australia \\ Correspondence should be addressed to Xiquan Weng; gzxiquanweng@163.com
}

Received 24 September 2019; Revised 20 November 2019; Accepted 30 December 2019; Published 25 January 2020

Academic Editor: Lucia Lopalco

Copyright ( $\odot 2020$ Guoqin Xu et al. This is an open access article distributed under the Creative Commons Attribution License, which permits unrestricted use, distribution, and reproduction in any medium, provided the original work is properly cited.

Purpose. To identify noninvasive immune biomarkers of exercise-induced immunosuppression using the iTRAQ proteomics technique. Methods. Fifteen healthy males were recruited and subjected to a four-week incremental treadmill running training program. After each week of training, $\mathrm{WBC}$ counts and $\mathrm{CD} 4^{+}$and $\mathrm{CD} 8^{+}$lymphocytes were measured to monitor the immune function status. iTRAQ proteomics technology was used to identify differential proteins and their characteristics in urine. Results. Our data showed that the WBC counts, $\mathrm{CD} 4^{+}$lymphocytes, and $\mathrm{CD} 4^{+} / \mathrm{CD} 8^{+}$ratio decreased by more than $10 \%$ after four weeks of training, suggesting exercise-induced immunosuppression. A total of 1854 proteins were identified in urine during the incremental running using the iTRAQ technology. Compared with the urine before training, there were 89, 52, 77, and 148 proteins significantly upregulated and 66, 27, 68, and 114 proteins significantly downregulated after each week, respectively. Among them, four upregulated proteins, SEMG-1, PIP, PDGFRL, and NDPK, increased their abundance with the increased exercise intensity. Bioinformatics analysis indicates that these proteins are involved in stress response and immune function. Conclusion. Four weeks of incremental treadmill running induced immunosuppression in healthy males. By using iTRAQ proteomics, four proteins in the urine, SEMG-1, PIP, PDGFRL, and NDPK, were found to increase incrementally with the increased exercise intensity, which have the potential to be used as noninvasive immune biomarkers of exercise-induced immunosuppression.

\section{Introduction}

Exercise-induced immunosuppression is a common medical problem that affects the training regimen in competitive sports [1]. During exercise-induced immunosuppression, the symptoms caused by acute respiratory infections may interfere with training and lead to the decline of mental attention, muscle strength, and aerobic ability during training for elite athletes [2,3]. These symptoms significantly affect sports training and sports performance and increase athletes' risk of further illness and injury [1]. Although a large number of studies have shown that nutrient supplementation can effectively prevent the occurrence of exerciseinduced immunosuppression [4-6], there are also studies suggesting that nutrient supplementation does not blunt the prolonged exercise-induced reduction in immunity [7].
Therefore, it is important to understand the characteristics of immune function with increased training load, which will play an important role in the early recognition and intervention of exercise-induced immunosuppression [8].

The degree of long-term exercise-induced impairment in the immune function of athletes mainly depends on exercise intensity $[9,10]$. In 1902, Larrabee reported for the first time that the exercise load of a marathon exceeded the limits that the body could tolerate, as the body's inflammatory response such as phagocytosis was evident, and neutrophils increased significantly after a marathon race [11]. In the absence of food intake, long-term ( $>1.5$ hours) moderate to high-intensity $\left(50 \%-77 \% \mathrm{VO}_{2} \mathrm{max}\right)$ exercise leads to the highest degree of immunological impairment [1]. In general, moderate exercise, defined as exercise intensity in the range of $40 \%$ to $60 \%$ of the maximum heart rate (HRmax) for 5 to 
60 minutes, can enhance the body's immune function and reduce the incidence of upper respiratory tract infection (URTI) [12-14]. Excessive exercise, defined as $70 \%$ to $80 \%$ of HRmax for more than 60 minutes, has been demonstrated to have adverse effects on the immune system $[15,16]$. As such, the infection rate of athletes who perform intense training increases significantly, indicating that once the training intensity reaches a threshold, the greater the intensity, the greater the immunosuppression and the risk of infection [17]. As a result, the relationship between exercise intensity/ amount and URTI susceptibility forms a "J" curve [18-20], and the period of immunosuppression after high-intensity exercise is called "open window" period [18].

The early prediction of immune function changes by monitoring biomarkers in the course of high-intensity training or in the early stages of the competition to avoid exercise-induced immunosuppression is essential to optimize sports training and competition. Changes in immune response factors during intense training can be used as indicators of overtraining [21]. Kakanis et al. [22] found that, after 2 hours of $90 \% \mathrm{VO}_{2}$ cycling exercise, $\mathrm{CD}^{+}$(Th1/Th2) cell levels changed immediately after exercise, while secreted cytokines such as IL-2, TNF (Th1), IL-6, and IL-10 (Th2) were altered 4 hours after exercise. Tuan et al. [23] conducted high-intensity exercise training for 3 consecutive days on healthy volunteers $\left(\mathrm{VO}_{2} \max 85 \%, 30 \mathrm{~min}\right.$ per day) and found that the mitochondrial transmembrane potential (MTP) of peripheral blood leucocytes decreased immediately and was still lower 24 hours after the last exercise bout, which returned to normal level 72 hours after exercise. It is believed that the mitochondrial transmembrane potential is a functional marker of leukocyte viability and can be used to monitor the immune function of short-term high-intensity exercise. The above studies have shown that although many researchers try to find early diagnostic indicators of exerciseinduced immunosuppression, they only focus on limited markers of immune function. The testing of immunomodulation indicators is complex and the monitoring of only a single biomarker and/or one time point often fails to provide a diagnosis [24]; thus, measuring the coexpression of multiple biomarkers and at multiple time points is essential for the diagnosis of immunomodulation [25].

Urine contains cellular and biochemical components derived from glomerular filtration of plasma, renal tubular excretion, and urogenital secretions [26]. Urinary proteins have been used as a noninvasive biomarker that can accurately monitor the body's stress under various psychophysiological changes and identify the body's condition in strenuous or unaccustomed exercise, competitions, overtraining, and improper recovery in sports [27, 28]. Urine is also an ideal source of biomarkers because it contains less lipid and more polypeptides, which are much higher in serum or tissue [29]. The development of proteomics technology provides a high-throughput, efficient, accurate, and sensitive research platform and enables the investigation of the relationship between exercise-induced immunomodulation and urine protein components [30].

In recent years, iTRAQ has been widely used as an in vitro labeling technique for polypeptides [31]. Extensive research [32-38] has shown that the application of iTRAQ technology can be used to identify disease-specific protein markers. Utilizing iTRAQ proteomics, this study aimed to determine the effects of 4 weeks of incremental treadmill running on the characteristics of urinary proteomics and then identify noninvasive immune biomarkers of exerciseinduced immunosuppression.

\section{Methods}

2.1. Participants. Fifteen healthy males were recruited from the student cohort of Guangzhou Sport University. The inclusion criteria included the following: nonsmoker and nondrinker, no regular high-intensity exercise training, no medication two weeks before the experiment, and no severe exercise or fatigue in the past three days. The study was approved by the Guangzhou Sport University Ethics Committee. Subjects were informed of the aims and procedures of the study and provided written informed consent prior to enrolment into the study. The baseline characteristics of the subjects are shown in Table 1.

2.2. Exercise Protocol. All subjects underwent maximum oxygen uptake testing on a treadmill. The $\mathrm{VO}_{2}$ max protocol began with an intensity of $8.0 \mathrm{~km} / \mathrm{h}$ and consisted of increments of $1 \mathrm{~km} / \mathrm{h}$ every $1 \mathrm{~min}$ by increasing the speed until volitional exhaustion. The criteria for reaching $\mathrm{VO}_{2} \max$ were determined by meeting at least 2 of the following [39]: (1) no further increase in oxygen uptake with increasing exercise workload, (2) a respiratory exchange ratio greater than 1.10, and (3) heart rate at or above the age-predicted maximal (using equation 220-age). The $\mathrm{VO}_{2} \max$ data was utilized to determine the corresponding running speed [40], and the subjects commenced 4-week incremental treadmill training 5 days per week, with training intensity adjusted each week [41]. Training intensity for the first week (W1) was $60 \% \mathrm{VO}_{2}$ max; for the second week (W2), 70\% $\mathrm{VO}_{2} \mathrm{max}$; for the third week (W3), $80 \% \mathrm{VO}_{2} \mathrm{max}$; and the fourth week (W4), 90\% $\mathrm{VO}_{2}$ max. The daily training program adopted an intermittent training mode, and the total running time was between 48 and 60 minutes. The detailed training program and the distance per week are shown in Figure 1.

2.3. Sample Collection. Before the training program, and at the end of each training week, fasting venous blood and midstream urine were collected at seven o'clock on each Sunday morning. Briefly, venous blood was collected using EDTA anticoagulant vacuum tubes to measure white blood cell count in the whole blood and $\mathrm{CD}^{+}$and $\mathrm{CD}^{+}$lymphocytes. The white blood cell count was measured within $4 \mathrm{~h}$ after blood was drawn [42], and the CD $4^{+}$ and $\mathrm{CD}^{+}$lymphocytes were measured within $6 \mathrm{~h}$ after blood was drawn [43]. Following the collection of morning midstream urine, protease inhibitor cocktail (PMSF, $1 \mathrm{mmol} / \mathrm{L}$, Amresco) was added to the urine samples to avoid proteolysis [44]. Urine samples were placed in liquid nitrogen and then stored at $-80^{\circ} \mathrm{C}$ until further analysis. 
TABle 1: Subject characteristics.

\begin{tabular}{lcccccc}
\hline Age $(\mathrm{y})$ & Height $(\mathrm{cm})$ & Weight $(\mathrm{kg})$ & $\mathrm{BMI}\left(\mathrm{kg} / \mathrm{m}^{2}\right)$ & $\mathrm{RPE}$ & Relative $\mathrm{VO}_{2} \max (\mathrm{ml} / \mathrm{kg} / \mathrm{min})$ & $\mathrm{HRmax}(\mathrm{bpm})$ \\
\hline $19.2 \pm 0.7$ & $170.6 \pm 4.9$ & $61.55 \pm 6.58$ & $20.70 \pm 1.41$ & $6.1 \pm 0.4$ & $48.60 \pm 4.98$ & $200.7 \pm 0.8$ \\
\hline
\end{tabular}

BMI: body mass index; RPE: ratings of perceived exertion.

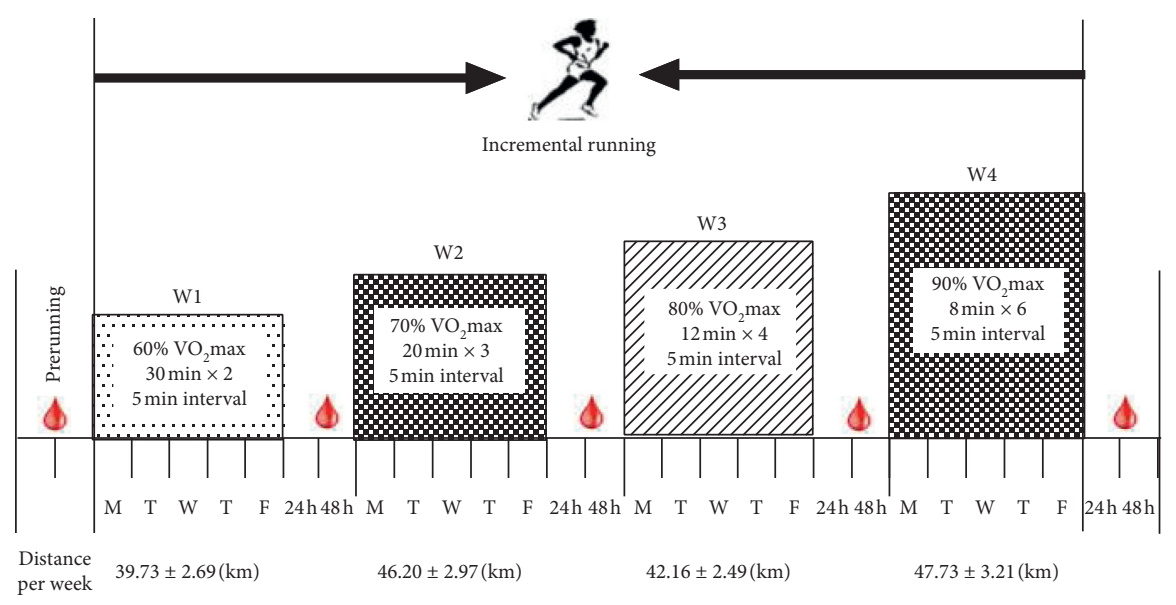

FIGURE 1: Four-week incremental treadmill running program and the distance per week.

2.4. Major Instruments and Reagents. The ADVIA ${ }^{\circledR} 120$ Hematology System and Full Blood Count Test Kit were from Siemens, Germany. BD FACSCalibur, and FITC mouse anti-human $\mathrm{CD} 3, \mathrm{APC}$ mouse anti-human $\mathrm{CD}^{+}$, and $\mathrm{PE}$ mouse anti-human $\mathrm{CD}^{+}$, APC mouse IgG1, $\mathrm{k}$ isotype control, PE mouse IgG1, $\mathrm{k}$ isotype control, FITC mouse IgG1 k isotype control, and CalibriteE 3-color kit were from BD Biosciences, USA. 8-plex iTRAQ Kit was from AB Sciex, USA. Pancreatin was from Promega, USA. First-dimension high $\mathrm{pH}-\mathrm{RP}$ liquid chromatography was measured via Shimadzu HPLC, USA. Second-dimension liquid chromatography was measured via Thermo Dionex Ultimate 3000 RSLCnano, USA. Mass Spectrometer was performed on a Thermo Scientific Q Exactive, USA. The ELISA Test Kits of SEMG-1, PIP, PDGFRL, and NDPK were from Shanghai Enzyme-linked Biotechnology Co., Ltd., China. The Multiskan Spectrum was from Thermo Scientific, USA.

2.5. Whole Blood Leukocytes and Their Classification Tests. White blood cell count, neutrophil count, and lymphocyte count were measured using the ADVIA 120 hematology analyzer according to the manufacturer's instructions (Bayer Corporation, Germany).

2.6. Lymphocyte $\mathrm{CD}^{+}$and $\mathrm{CD}^{+}$Tests. Blood cells were analyzed on a FACScan (BD Biosciences, USA) equipped with CellQuest ${ }^{\circledR}$ software. The flow cytometer was calibrated and standardized with the CalibriteE 3-color kit before analysis (IVD, BD Biosciences, USA), and then FITC-CD3, PE-CD8, and APC-CD4 were analyzed by flow cytometry using standard protocols provided by the manufacturer.

2.7. Experimental Workflow of iTRAQ Labeling and Analysis. In this study, the urine samples collected from all the participants at baseline and at the end of each week were thawed and combined into one urine sample for each time point and labeled using iTRAQ Reagent 8-plex kit (Sciex). The urine sample before the commencement of the training intervention (UW0) was labeled with labeling reagent 114, and the urine samples following the first week of training (UW1), the second week (UW2), the third week (UW3), and the fourth week (UW4) were labeled with labeling reagents 115, 117, 119, and 121, respectively. Each labeled urine sample was analyzed twice via iTRAQ, with two technical replicates of each sample [45]. The basic flow of the iTRAQ quantitative proteomics experiment [46] is shown in Figure 2.

2.8. Database Search and Screening for Differential Proteins. Protein searches were performed using the ProteinPilotTM Software 5.0 (AB Sciex). After the search was completed, the unused value was selected in the database Uniprot human, unused (ProtScore) for the search result (iTRAQ original data), unused $\geq 1.3$ was set, and a protein with a confidence level of $95 \%$ or more was set as the analysis target. ProteinPilotTM FDR analysis was performed and the records beginning with "RRRRRR" in the search results were removed, and proteins with no quantitative information and proteins with poor repeatability $(|C . V| \geq 0.5)$ were removed. On the basis of protein analysis, differential proteins were screened. $A V G \geq 1.5$ was set to indicate an upregulated protein, and $A V G \leq 0.67$ was set to indicate a downregulated protein [47].

2.9. Bioinformatics Analysis. For the "co-upregulation" and "co-downregulation" of differential proteins in incremental treadmill running exercises, comprehensive biological functional annotations were performed using the Uniprot database website and DAVID data analysis software (http:// david.abcc.ncifcrf.gov/home.jsp) [48]. To obtain the overall distribution of differentially expressed proteins in various 


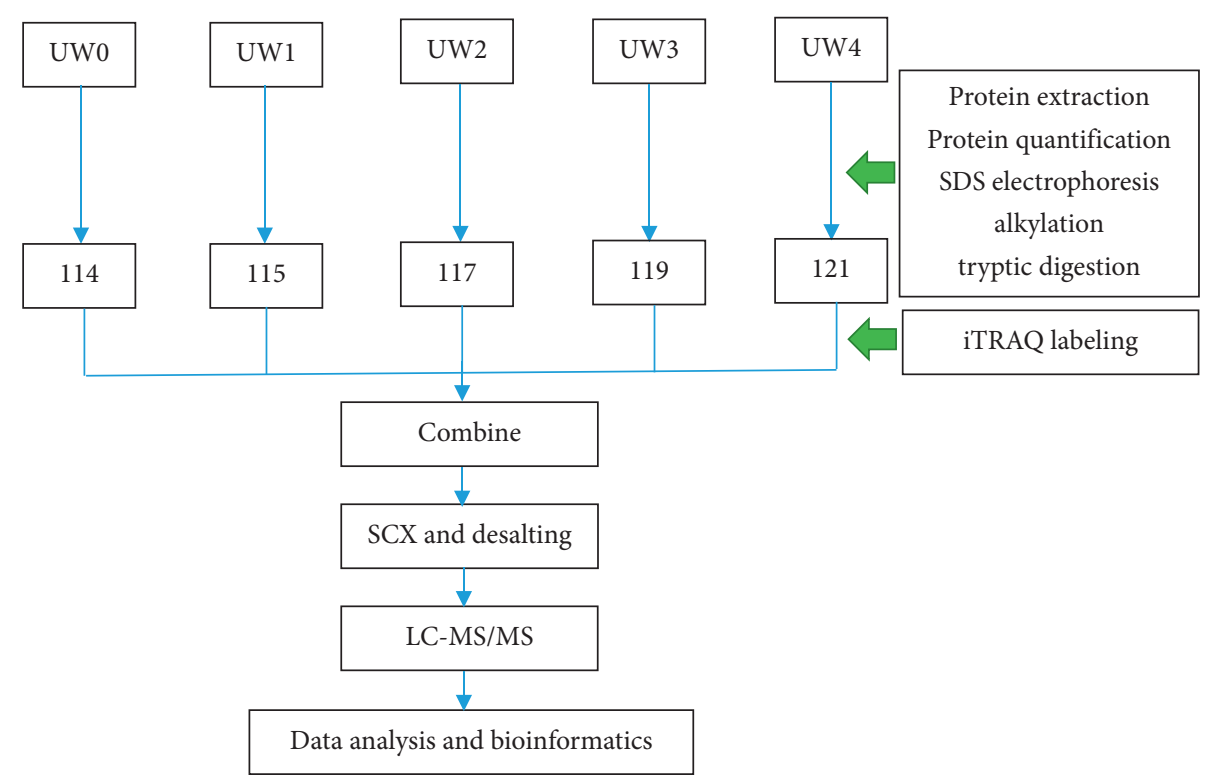

(a)

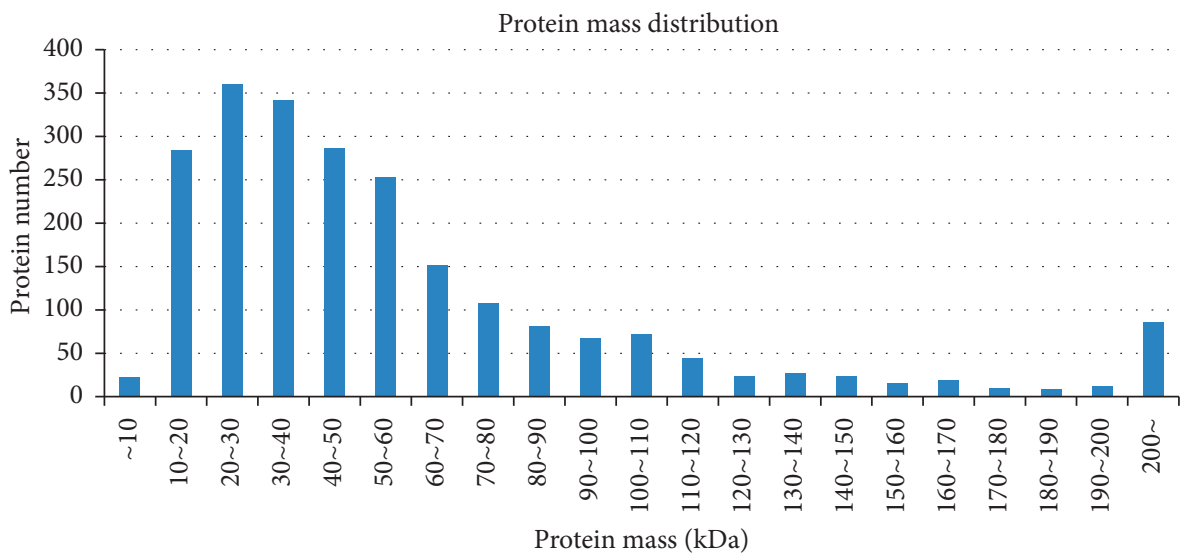

(b)

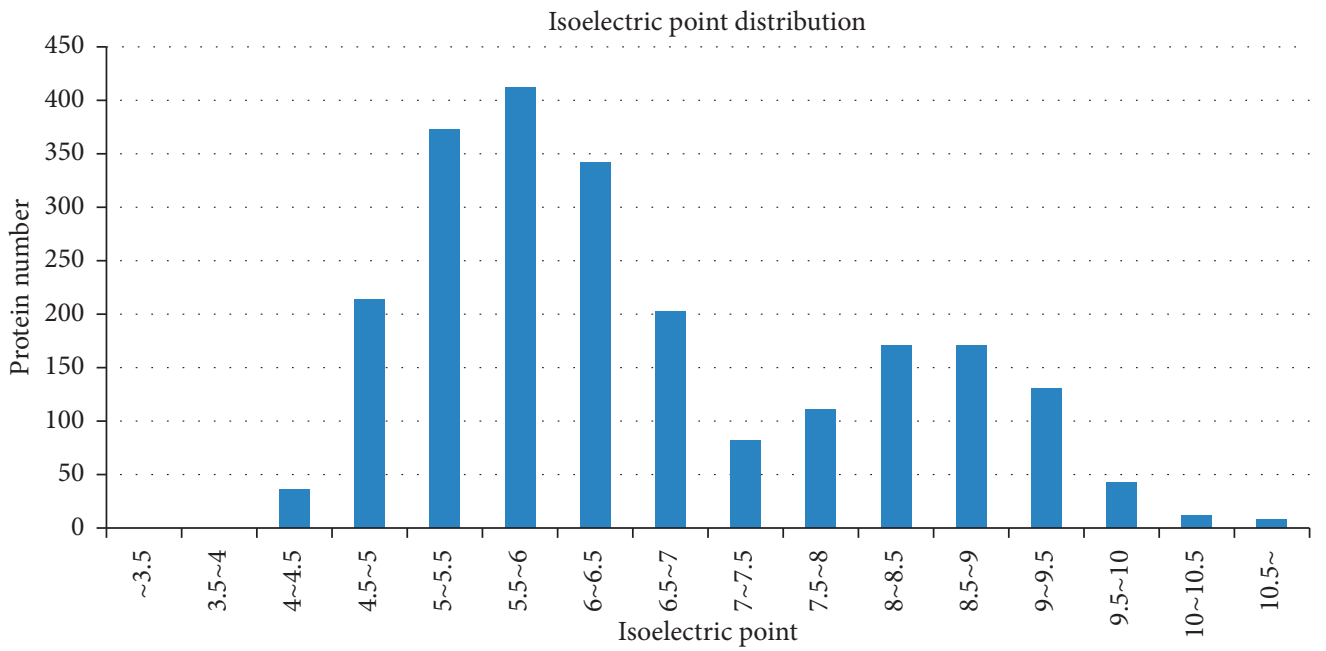

(c)

Figure 2: Continued. 


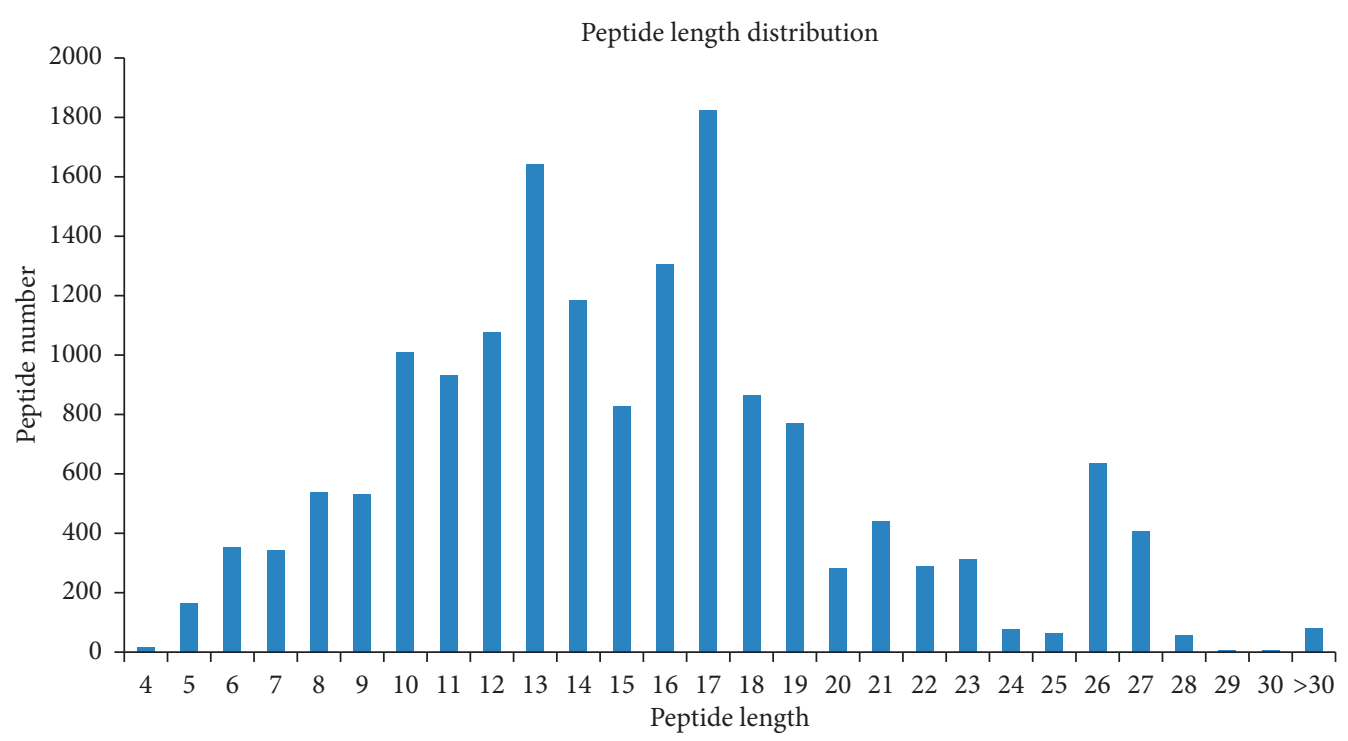

(d)

FIgURE 2: iTRAQ labeling and basic data analysis. (a) Experimental workflow for iTRAQ labeling and analysis. iTRAQ 8-plex labeling was performed on the collected urine samples. The labeled fractions were combined and subjected to strong cation exchange (SCX) chromatography and desalting, followed by separation using liquid chromatography mass spectrometry (LC-MS/MS), and data analysis and bioinformatics analysis. (b) Mass distribution of all the identified proteins. The horizontal axis is the molecular weight of the identified protein (Unit: kiloDalton, $\mathrm{kDa}$ ). The vertical axis is the number of proteins identified. (c) The isoelectric point map of all the identified proteins. The horizontal axis is the isoelectric point of the identified protein and the vertical axis is the number of proteins identified. (d) Peptide length distribution of all the identified proteins. The graph shows the percentage of peptides of different lengths in all peptides. The abscissa is the number of peptide amino acid residues, and the ordinate is the number of peptides of this length.

functions, genetic enrichment analysis based on Gene Ontology (GO) of biological processes, cellular component, and molecular functions was performed, and the functional information of differentially expressed proteins was obtained. According to the biological functions of the differential proteins and the physiological reaction processes involved in the organism, GO clustering was performed to analyze the possible relationships between the differential proteins and the signal pathways that these proteins may participate in. The differential protein interaction network was analyzed by the string database $[49,50]$ (https://string$\mathrm{db} . o r g /)$ to observe the interaction patterns between the differential proteins and to explore the relationship between them and the changes in immune function during the incremental treadmill running program.

2.10. ELISA Tests. The protein content of SEMG-1, PIP, PDGFRL, and NDPK was tested according to the manufacturer's instructions of the ELISA test kits (Shanghai Enzyme-linked Biotechnology, China), using a Multiskan Spectrum (Thermo Scientific, USA).

2.11. Statistical Analysis. Data was analyzed using IBM SPSS 22.0 software. One-way ANOVA was used for analyzing the related data. Data were expressed as mean \pm standard deviation. $P<0.05$ was considered statistically significant.

\section{Results}

\subsection{Changes in Immune Function}

3.1.1. Changes in Leukocyte Counts in Blood. The white blood cell count showed a progressively decreasing trend and was $15 \%$ lower by the end of the 4 th week (W4) of the incremental training, compared with that before training (W0) (Table 2; $P<0.05$ ). The major reduction in leukocyte counts was neutrophils, which progressively decreased throughout the training program (W4 was $27.4 \%$ lower than that of W0, Table 2; $P<0.05$ ). There was no significant difference in the lymphocyte count (Table 2).

3.1.2. Changes of $C D 4^{+}$and $C D 8^{+}$Lymphocytes in Blood. The percentage of $\mathrm{CD} 4^{+}$lymphocytes was $11.8 \%$ lower by the end of the fourth week compared with W0 (Table 3; $P<0.05)$. Conversely, the percentage of $\mathrm{CD}^{+}$lymphocytes increased after 4 weeks of the incremental load training program (by $27.3 \%, P<0.05$ ). Of note, there were also significantly higher $\mathrm{CD}^{+}$lymphocytes at W1 (Table 3; $P<0.05$ ) and W3 (Table 3; $P<0.05$ ). The ratios of $\mathrm{CD}^{+} /$ $\mathrm{CD} 8^{+}$lymphocytes were significantly lower in $\mathrm{W} 1, \mathrm{~W} 2, \mathrm{~W} 3$, and W4 compared to W0 (Table 3; $P<0.05$ ).

3.2. Differential Protein Status in Urine Proteomics during the Change in Immune Function. By performing proteomics 
TAвLE 2: Changes of white blood cell counts and their classification counts during 4 weeks of incremental treadmill running.

\begin{tabular}{lcccrc}
\hline & W0 & W1 & W2 & W3 & W4 \\
\hline White blood cell count $(\times 109)$ & $7.03 \pm 1.70$ & $6.56 \pm 1.34$ & $6.25 \pm 1.06$ & $6.49 \pm 0.94$ & $5.97 \pm 0.95^{*}$ \\
Neutrophil count $(\times 109)$ & $3.71 \pm 1.61$ & $3.22 \pm 0.96$ & $3.07 \pm 0.68$ & $3.16 \pm 0.69$ & $2.69 \pm 0.60^{* *}$ \\
Lymphocyte count $(\times 109)$ & $2.57 \pm 0.50$ & $2.61 \pm 0.58$ & $2.48 \pm 0.37$ & $2.58 \pm 0.44$ & $2.51 \pm 0.64$ \\
\hline
\end{tabular}

${ }^{*} p<0.05 ;{ }^{* *} p<0.01$, compared with W0.

TABLE 3: Changes of $\mathrm{CD}^{+}$and $\mathrm{CD}^{+}$lymphocytes in the blood during 4 weeks of incremental treadmill running.

\begin{tabular}{lccccc}
\hline & W0 & W1 & W2 & W3 & W4 \\
\hline CD4+ (\%) & $54.66 \pm 7.84$ & $51.36 \pm 6.26$ & $50.90 \pm 7.99$ & $51.14 \pm 5.25$ & $48.19 \pm 5.61^{* *}$ \\
$\mathrm{CD} 8+(\%)$ & $32.23 \pm 9.04$ & $39.77 \pm 7.81^{* *}$ & $36.97 \pm 8.46$ & $38.26 \pm 4.24^{*}$ & $41.03 \pm 7.07^{* *}$ \\
$\mathrm{CD}^{+} / \mathrm{CD}^{+}$ & $1.88 \pm 0.73$ & $1.37 \pm 0.47^{* *}$ & $1.50 \pm 0.58^{*}$ & $1.36 \pm 0.25^{* *}$ & $1.23 \pm 0.36^{* *}$ \\
\hline
\end{tabular}

${ }^{*} p<0.05 ;{ }^{* *} p<0.01$, compared with W0.

quantitative measurements in the urine, it was found that there were differential proteins in the subject's combined urine samples after each one-week training period. As shown in Table 4, compared with preexercise urine (UW0), there were 87 upregulated and 64 downregulated proteins in the urine after the first week of exercise (UW1). After the second week of the exercise, the number of differential proteins in urine (UW2) was significantly reduced. Subsequently, the number of differential proteins in urine gradually increased with the increase in exercise intensity, especially for the number of differential proteins in urine after the 4th week of intense exercise (UW4). Compared with UW0, both the number of upregulated proteins and downregulated proteins were almost doubled.

As shown in Figure 3 and Tables 5 and 6, further analysis of the differential proteins showed that there were $15 \mathrm{co}-$ upregulated proteins and 9 co-downregulated proteins in the urine after each week of training compared to UW0. Among them, four upregulated proteins, including Semenogelin-1, Prolactin-inducible protein, Platelet-derived growth factor receptor-like protein, and Nucleoside diphosphate kinase, increased with increasing exercise intensity. In addition, some differential proteins increased with exercise intensity from the second week of the exercise, such as Glycerol-3phosphate phosphatase, Secretogranin-1, Prosaposin, and Nephronectin (Fragment). Some proteins also decreased further with exercise intensity from the second week of the exercise, such as Immunoglobulin kappa constant, Immunoglobulin lambda variable 3-21, Signal peptide CUB and EGF-like domain-containing protein 2, and Uromodulin.

3.3. Bioinformatics Analysis. To further understand the role of the above 24 differential proteins in immune function during the incremental treadmill-training program, we used the Uniprot database website and DAVID data analysis software to analyze the signaling pathways that may be related to these proteins and the possible differences between these proteins. Figure 4 shows various GO enrichments of 24 differential proteins, including biological processes (top three: immune system processes, transport, and small molecule metabolic process), molecular functions (top three: ion binding, antigen binding, and transmembrane transporter activity), and cellular composition (top three: extracellular area, extracellular space, and plasma membrane).

\subsection{Transcriptional Regulatory Network between Differential} Proteins. The analysis of the 24 differential proteins interaction networks through the STRING database (https:// string-db.org/) was undertaken. No corresponding genes were found for four proteins by the name in Homo sapiens, including IGKC, IGLV3-21, IGLV4-69, and IGLV2-18, and the genes of the other 20 proteins in the interaction network are shown in Figure 5. For functional enrichment in the network, biological process (GO), in the pathway analysis, there are 10 genes count in gene set pathways of positive regulation of response to stimulus (pathway ID, GO: 0048584). This pathway also includes ten differential proteins, namely, Apolipoprotein A-I (APOA1), Beta-2-glycoprotein $1(\mathrm{APOH})$, Complement decay-accelerating factor (CD55), Adhesion G-protein-coupled receptor G1 (Fragment) (GPR56), Leucine-rich alpha-2-glycoprotein (LRG1), Nucleoside diphosphate kinase (NME2), Nephronectin (Fragment) (NPNT), Prosaposin (PSAP), Serotransferrin (TF), and 14-3-3 protein zeta/delta (Fragment) (YWHAZ). For molecular function (GO), there are two genes count in gene set pathways of IgG binding (pathway ID, GO: 0019864). This pathway also contains two differential proteins, Prolactin-inducible protein (PIP), and Uromodulin (UMOD). This pathway is associated with the immunological function of the organism together with three other proteins: Immunoglobulin lambda variable 3-21, Immunoglobulin lambda variable 4-69, and Immunoglobulin lambda variable 2-18.

3.5. ELISA Validation. Four of the identified differential proteins in the urine were validated by ELISA (Table 7). During incremental running, the content of SEMG-1, PIP, PDGFRL, and NDPK was increased with increasing exercise intensity. Compared with W0 (before training), upregulation was observed for PIP and NDPK from W1, SEMG-1 from W2, and PDGFRL from W3 (Table 7; $P<0.05$ ). 
TABLE 4: Changes in the number of differential proteins in urine during exercise-induced immunosuppression.

\begin{tabular}{|c|c|c|c|c|c|c|c|c|}
\hline & \multicolumn{2}{|c|}{ Compared with UW0 } & \multicolumn{2}{|c|}{ Compared with UW1 } & \multicolumn{2}{|c|}{ Compared with UW2 } & \multicolumn{2}{|c|}{ Compared with UW3 } \\
\hline & Upregulation & Downregulation & Upregulation & Downregulation & Upregulation & Downregulation & Upregulation & Downregulation \\
\hline UW1 & 87 & 64 & & & & & & \\
\hline UW2 & 50 & 25 & 36 & 35 & & & & \\
\hline UW3 & 75 & 66 & 44 & 52 & 42 & 42 & & \\
\hline UW4 & 146 & 112 & 101 & 108 & 113 & 115 & 104 & 90 \\
\hline
\end{tabular}

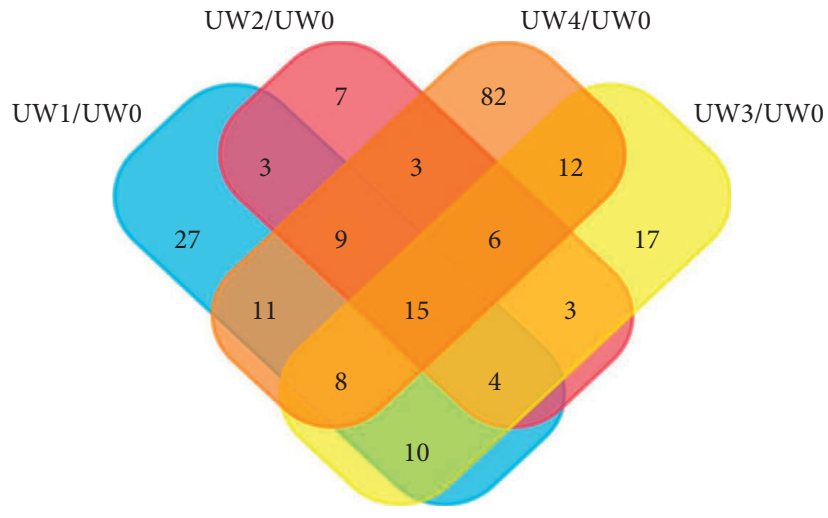

The amount of co-upregulated proteins

(a)

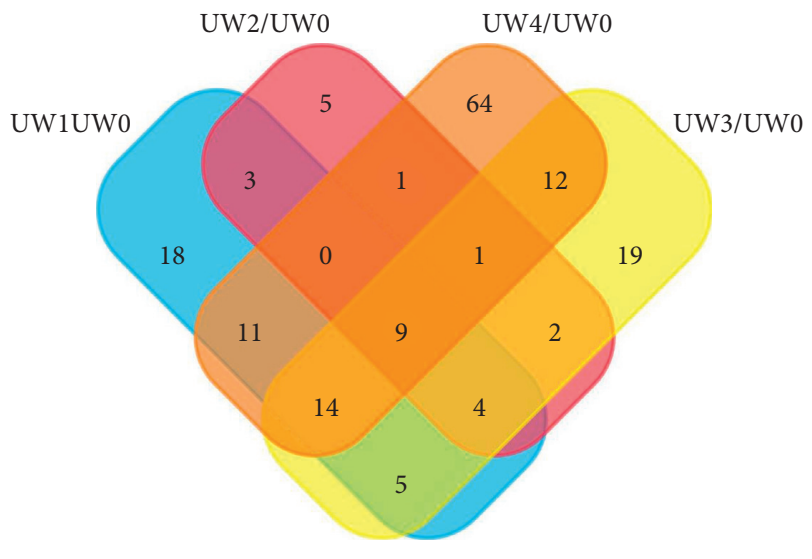

The amount of co-downregulated proteins

(b)

FIGURE 3: Compared with UW0, the amount of co-upregulated and co-downregulated proteins among the UW1, UW2, UW3, and UW4. (a) The amount of co-upregulated differential proteins. There were 15 co-upregulated proteins in the urine after each week of training compared to UW0. (b) The amount of co-downregulated differential proteins. There were 9 co-downregulated proteins in the urine after each week of training compared to UW0.

TABLE 5: Multiples of differential co-upregulation protein content in urine during exercise-induced immunosuppression.

\begin{tabular}{|c|c|c|c|c|c|c|}
\hline Accession & Name & Gene & UW1/UW0 & UW2/UW0 & UW3/UW0 & UW4/UW0 \\
\hline A6NDG6 & Glycerol-3-phosphate phosphatase & PGP & 6.402 & 1.579 & 5.065 & 6.770 \\
\hline P02647 & Apolipoprotein A-I & APOA1 & 2.838 & 2.036 & 5.556 & 1.616 \\
\hline P02787 & Serotransferrin & $\mathrm{TF}$ & 1.641 & 2.126 & 3.919 & 1.542 \\
\hline P04279 & Semenogelin-1 & SEMG1 & 5.971 & 6.339 & 32.16 & 38.385 \\
\hline P05060 & Secretogranin-1 & CHGB & 2.981 & 2.452 & 2.907 & 6.679 \\
\hline P08183 & Multidrug resistance protein 1 & $\mathrm{ABCB} 1$ & 2.754 & 3.133 & 1.888 & 1.941 \\
\hline P12273 & Prolactin-inducible protein & PIP & 51.665 & 50.957 & 56.903 & 61.536 \\
\hline Q02383 & Semenogelin-2 & SEMG2 & 7.977 & 7.670 & 28.796 & 40.938 \\
\hline Q15198 & Platelet-derived growth factor receptor-like protein & PDGFRL & 2.489 & 3.311 & 21.878 & 22.699 \\
\hline Q8N436 & Inactive carboxypeptidase-like protein X2 & CPXM2 & 1.791 & 1.850 & 1.683 & 1.583 \\
\hline C9JIZ6 & Prosaposin & PSAP & 2.382 & 1.863 & 4.002 & 8.306 \\
\hline D6RH31 & Nephronectin & NPNT & 1.969 & 1.611 & 1.739 & 2.605 \\
\hline E7EX29 & $14-3-3$ protein zeta/delta & YWHAZ & 1.786 & 1.675 & 1.556 & 2.512 \\
\hline H3BSN7 & Adhesion G-protein-coupled receptor G1 & GPR56 & 5.248 & 4.831 & 4.875 & 4.131 \\
\hline Q32Q12 & Nucleoside diphosphate kinase & NME2 & 1.905 & 1.905 & 1.585 & 2.188 \\
\hline
\end{tabular}

\section{Discussion}

In the current study, we found that WBC counts, $\mathrm{CD} 4^{+}$lymphocytes, and $\mathrm{CD} 4^{+} / \mathrm{CD}^{+}$ratio decreased after four weeks of incremental treadmill training, suggesting exercise-induced immunosuppression. By using iTRAQ technology, we have identified a total of 1854 proteins in the urine samples. Compared with the urine before training, there were $89,52,77$, and 148 proteins significantly upregulated and 66, 27, 68, and 114 proteins significantly downregulated after each week, respectively. Among them, four upregulated proteins, SEMG-1, PIP, PDGFRL, and NDPK, increased their abundance with the increased exercise intensity. We further used bioinformatics analysis and found that these proteins are involved in stress response and immune function. To our knowledge, this is the first study to 
TABle 6: Multiples of differential co-downregulation protein content in urine during exercise-induced immunosuppression.

\begin{tabular}{|c|c|c|c|c|c|c|}
\hline Accession & Name & Gene & UW1/UW0 & UW2/UW0 & UW3/UW0 & UW4/UW0 \\
\hline P01834 & Immunoglobulin kappa constant & IGKC & 0.308 & 0.667 & 0.530 & 0.113 \\
\hline P02749 & Beta-2-glycoprotein 1 & $\mathrm{APOH}$ & 0.615 & 0.605 & 0.619 & 0.556 \\
\hline P02750 & Leucine-rich alpha-2-glycoprotein & LRG1 & 0.264 & 0.400 & 0.606 & 0.443 \\
\hline P80748 & Immunoglobulin lambda variable 3-21 & IGLV3-21 & 0.520 & 0.603 & 0.337 & 0.211 \\
\hline A0A075B6H9 & Immunoglobulin lambda variable 4-69 & IGLV4-69 & 0.501 & 0.441 & 0.619 & 0.437 \\
\hline A0A075B6J9 & Immunoglobulin lambda variable $2-18$ & IGLV2-18 & 0.643 & 0.592 & 0.608 & 0.570 \\
\hline A0A0A0MTC8 & $\begin{array}{l}\text { Signal peptide, CUB and EGF-like } \\
\text { domain-containing protein } 2\end{array}$ & SCUBE2 & 0.545 & 0.667 & 0.643 & 0.550 \\
\hline H7BY55 & Complement decay-accelerating factor & CD55 & 0.637 & 0.637 & 0.347 & 0.608 \\
\hline X6RBG4 & Uromodulin & UMOD & 0.453 & 0.631 & 0.477 & 0.349 \\
\hline
\end{tabular}

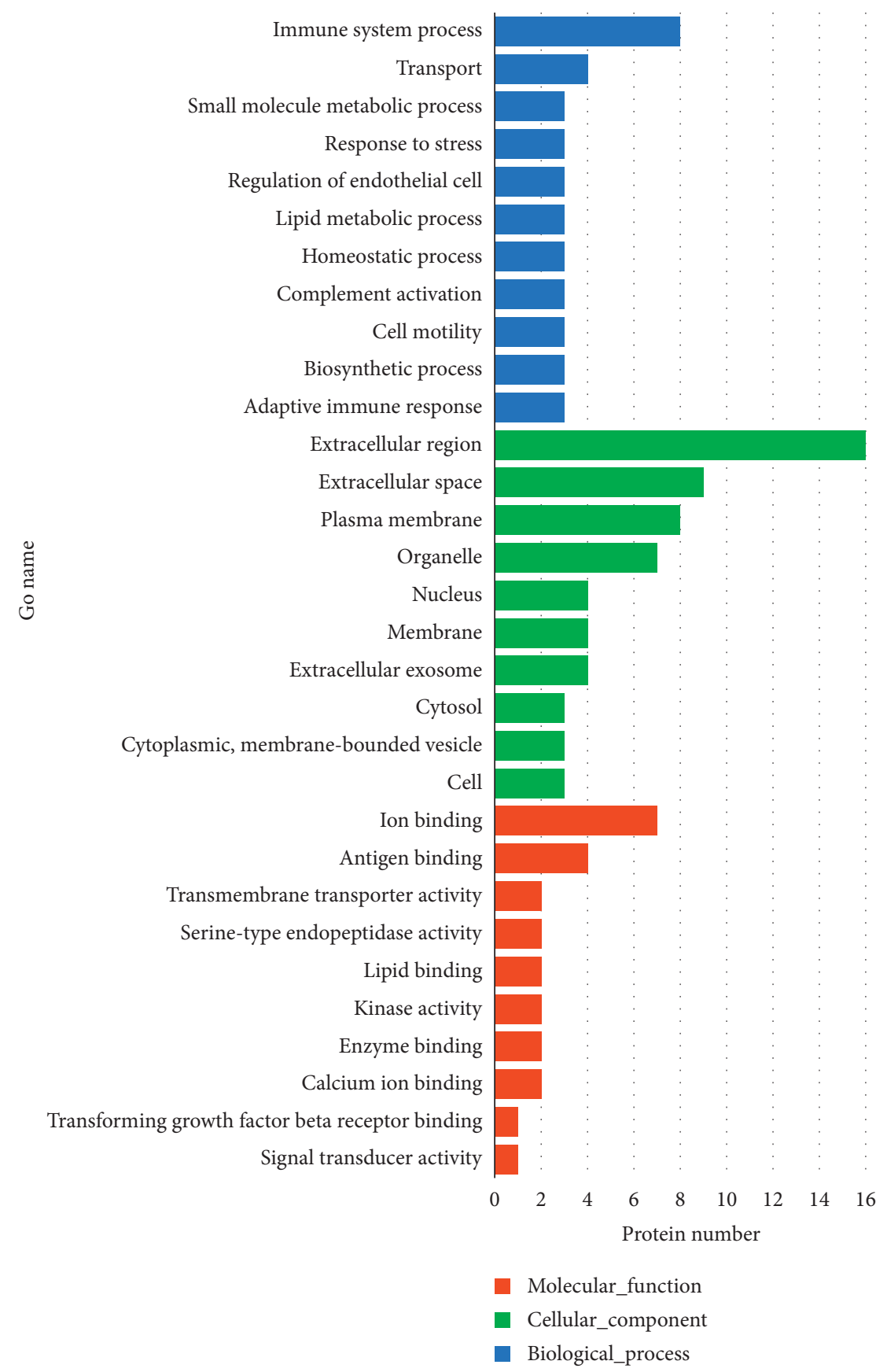

Figure 4: Gene Ontology (GO) annotation of 24 codifferential proteins. The codifferential proteins were divided into 3 categories: molecular function (MF), cellular component (CC), and biological process (BP). Each enumerated annotation is assigned by the enrichment protein number. The top 10 components for MF, CC, and BP of the codifferential proteins according to the GO database are shown. 


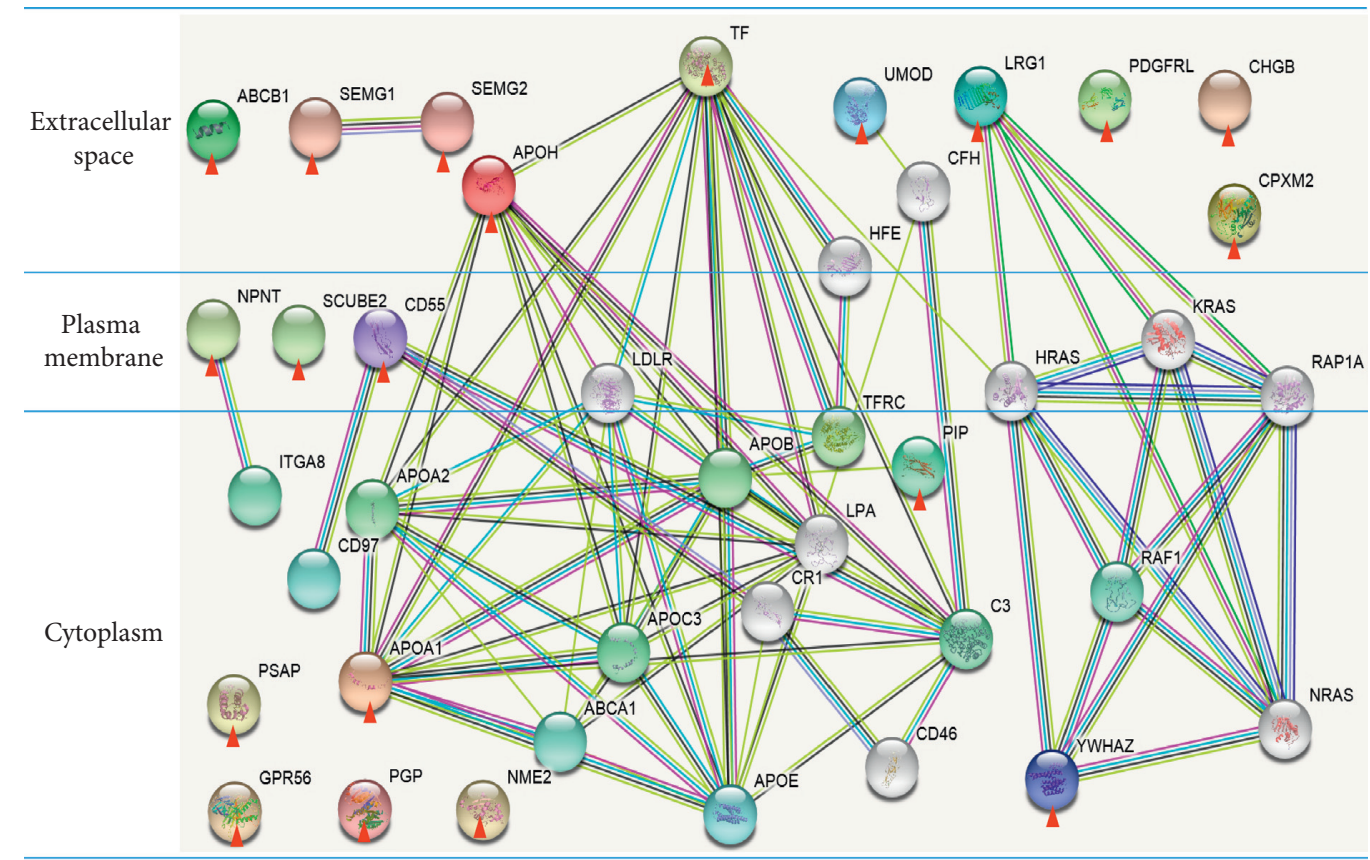

$\triangle$ Marking the differential protein

FIgURE 5: The genes of differential proteins in the interaction network. For functional enrichment in the network, biological process (GO), in the pathway analysis, there are 10 genes count in gene set pathways of positive regulation of response to stimulus (pathway ID, GO: 0048584). Molecular Function (GO), there are two genes count in gene set pathways of IgG binding (pathway ID, GO: 0019864). The red line shows Gene Fusions, the green line indicates Neighborhood in the Genome, the blue line indicates Cooccurrence across Genomes, the purple line indicates Experimental/Biochemical Data, the yellow line indicates text mining evidence, the light blue line indicates database evidence, and the black line indicates coexpression evidence.

TABLE 7: Changes of differential proteins in the urine during 4 weeks of incremental treadmill running.

\begin{tabular}{|c|c|c|c|c|c|}
\hline & W0 & W1 & W2 & W3 & W4 \\
\hline SEMG1 $(\mu \mathrm{g} / \mathrm{ml})$ & $2.57 \pm 0.81$ & $3.63 \pm 1.26$ & $4.13 \pm 1.40^{* *}$ & $4.51 \pm 1.72^{* *}$ & $6.61 \pm 2.35^{* *}$ \\
\hline PIP $(\mu \mathrm{g} / \mathrm{ml})$ & $55.68 \pm 18.38$ & $79.98 \pm 24.85^{*}$ & $81.45 \pm 21.97^{*}$ & $84.55 \pm 29.31^{* *}$ & $113.79 \pm 37.32^{* *}$ \\
\hline PDGFRL $(\mu \mathrm{g} / \mathrm{ml})$ & $4.29 \pm 1.01$ & $5.61 \pm 2.08$ & $5.64 \pm 2.12$ & $7.30 \pm 1.92^{* *}$ & $10.98 \pm 3.38^{* *}$ \\
\hline NDPK $(\mu \mathrm{g} / \mathrm{ml})$ & $9.82 \pm 3.20$ & $15.70 \pm 4.54^{*}$ & $16.54 \pm 5.37^{* *}$ & $20.39 \pm 8.54^{* *}$ & $29.91 \pm 8.37^{* *}$ \\
\hline
\end{tabular}

${ }^{*} p<0.05,{ }^{* *} p<0.01$, Compared with W0.

employ the iTRAQ technology to analyze urine proteomics of exercise-induced immunosuppression. Our data suggested that some urine proteins could be used as biomarkers of exercise-induced immunosuppression, which are relatively easy to monitor athletes.

High-intensity and large-volume exercise training can cause significant changes in the immune parameters of the body's nonspecific and specific immune system, especially the response of NK cells, and neutrophils, leading to the body's immunosuppression during a heavy training workload and for a few days after the training [18]. It has been widely reported that long-term high-intensity exercise training will have a strong negative impact on the immune function of the athletes, resulting in inhibition of immune function, increased susceptibility to various infectious diseases, and even lead to poor performance during intensive training [51]. This study confirmed that the subjects' white blood cell count, neutrophil count, $\mathrm{CD} 4^{+}$, and $\mathrm{CD} 4^{+} / \mathrm{CD} 8^{+}$ ratio were decreased significantly after 4 weeks of incremental treadmill exercise. Although the exercise intensity was relatively small during the first two weeks, the accumulation of daily exercise training also reduced the immune function. In particular, following the fourth week of high-intensity exercise training, a significant decrease was observed in the body's immune function (immunosuppression). This was evidenced by reductions in white blood cell count (15\%), neutrophil count (27.4\%), $\mathrm{CD} 4^{+}$lymphocytes $(11.8 \%), \mathrm{CD}^{+} / \mathrm{CD}^{+}$ratio $(34.6 \%)$, and an increase in $\mathrm{CD}^{+}$lymphocytes $(27.3 \%)$. The most important clinically relevant finding during exercise-induced immunosuppression is a higher risk of URTI [52]. While reported rates for URTI vary, up to $50 \%$ of fitness enthusiasts in high school and university training rooms have experienced respiratory infections [15]. It has also been reported that the occurrence rate of URTI for competitive swimmers exceeded $40 \%$ after 4 weeks of intense training [53], while 12 weeks of high-intensity training increased the incidence of URTI in tennis players [54]. 
It is interesting to note that the decline in the immune system can be accompanied by the contemporary occurrence of proteinuria during long and strenuous exercise [55]. The reason for the large number of differential proteins in the urine collected following the first week of training may be due to the subject's inability to adapt to the consecutive training of the first week [56]. As the body slowly adapts during the second week, the number of differential proteins in the urine is significantly reduced. When the exercise load increases, the number of differential proteins in the urine gradually increases, especially with high-intensity exercise. It has been shown previously that intense exercise-induced proteinuria is related to exercise intensity $[57,58]$ and that the doubling of urine proteins caused by high-intensity exercise in the fourth week suggests an increased glomerular permeability and kidney secretion caused by exercise stress. It has been previously reported that exercise intensity affects kidney function more than exercise load [59].

Of all the differentially expressed urinary proteins induced by incremental training, 15 proteins are consistently upregulated in all four time points, and 9 proteins are consistently downregulated in all four time points. Among them, four proteins SEMG-1, PIP, PDGFRL, and NDPK increased their abundance with increasing exercise intensity. SEMG-1 has been detected in the gastrointestinal tract, skeletal muscle [60], and normal human urine [61]. It is processed and presented by thymic antigen presenting cells and is likely to participate in shaping the $\mathrm{T}$-cell repertoire [62], which is involved in the regulation of immune function $[63,64]$. SEMG-1 is upregulated in exosomes secreted by vascular endothelial cells under hypoxic stress conditions [65] and is considered as a new predictor of renal damage [66]. PIP also plays an important role in immune regulation. It is abundantly present in saliva and bronchial submucosal glands and exerts mucosal immunity [67]. PIP binds to immunoglobulin G (IgG) [68] and CD4-T cell receptor $[69,70]$ to exert important biological functions [71-75]. The expression of PIP is regulated by immunoregulatory hormones, such as androgen and glucocorticoids [76]. Lack of PIP leads to impaired Th1 immune response [77]. The expression of PDGFRL is associated with blood pressure, heart quality, and insulin sensitivity [78, 79], while NDPK regulates angiogenesis [80], neuronal protection [81], and insulin secretion regulation [82]. Taken together, previous studies suggested that the differential protein abundance of SEMG1, PIP, PDGFRL, and NDPK in urine is related to the immune function and stress response. Our current results show that while the body's immune function is declining, as evidenced by the decreased white blood cells, $\mathrm{CD} 4^{+}$and $\mathrm{CD} 4^{+} / \mathrm{CD}^{+}$ratio, the four upregulated proteins in urine gradually increase during the incremental treadmill-training program. We, therefore, conclude that SEMG-1, PIP, PDGFRL, and NDPK may serve as noninvasive immune biomarkers for exercise-induced immunosuppression.

Through bioinformatics analysis, it was found that, during the process of exercise-induced immunosuppression, the components of the differential proteins in urine are mainly distributed in the extracellular region, extracellular space, and plasma membrane. The reason may be due to the increased destruction of the plasma membrane by free radicals, and proteins in the extracellular area, extracellular space, and the plasma membrane are more likely to enter the bloodstream [83] and then are filtered out with the increased permeability of the glomerular filtration membrane into the urine $[84,85]$. The biological processes of these differential proteins mainly perform immune system processes, transport, and small molecule metabolic processes.

Further analysis of the functional enrichments of these differential protein-gene interaction networks revealed that 10 genes of the differential proteins are related to the pathway of positive regulation of response to the stimulus in the biological process. In molecular function, 5 genes of the differential proteins are in the pathway of IgG binding. It is likely that the incremental treadmill running mobilized the body's intense stress response and adaptive immune compensation [86]. Meanwhile, due to the increase of free radicals and the relative lack of free radical scavenging ability induced by exercise stress [87], the disruption of normal membranous structures and the increase of cell membrane permeability initiated. As the ultrastructural changes of the glomeruli and tubules and the permeability of glomerular filtration membranes increase, protein filtration rate increases and the secretion of proteins by the kidney increases [88], resulting in an increased presence of urinary proteins, such as those related to stress regulation and immune function. Therefore, testing these proteins excreted in the urine can indirectly reflect the body's stress and immune function inhibition.

In summary, this current study has identified four differential proteins, SEMG-1, PIP, PDGFRL, and NDPK, as noninvasive immune biomarkers in urine for exercise-induced immunosuppression. Further studies are needed to validate the noninvasive biomarkers of exercise-induced immunosuppression, possibly in a different population (especially in females or elite athletes) or with a different training program. The sensitivity and specificity of each biomarker also need to be tested in future studies.

\section{Data Availability}

The ZIP data used to support the findings of this study are available from the corresponding author upon request.

\section{Ethical Approval}

All human experiments were carried out in accordance with the Chinese human Welfare Act. Ethical approval for these studies was obtained from the Ethics Committee of Guangzhou Sport University (NO: 15/003).

\section{Disclosure}

The authors declare that the results of the study are presented clearly, honestly, and without fabrication, falsification, or inappropriate data manipulation.

\section{Conflicts of Interest}

The authors have declared no conflicts of interest. 


\section{Acknowledgments}

This study was supported by the Sports Research of General Administration of Sport of China (GASC), 2014B019.

\section{References}

[1] M. Gleeson, "Immune function in sport and exercise," Journal of Applied Physiology, vol. 103, no. 2, pp. 693-699, 1985.

[2] N. P. Walsh, "Recommendations to maintain immune health in athletes," European Journal of Sport Science, vol. 18, no. 6, pp. 820-831, 2018.

[3] D. Buonocore, M. Negro, E. Arcelli, and F. Marzatico, "Antiinflammatory dietary interventions and supplements to improve performance during athletic training," Journal of the American College of Nutrition, vol. 34, no. sup1, pp. 62-67, 2015.

[4] H. Hemila, "The effect of nutrition on exercise-induced immunodepression," Nutrition Reviews, vol. 64, no. 10 Pt 1, pp. 476-477, 2006.

[5] A. Moreira, R. A. Kekkonen, L. Delgado, J. Fonseca, R. Korpela, and T. Haahtela, "Nutritional modulation of exercise-induced immunodepression in athletes: a systematic review and meta-analysis," European Journal of Clinical Nutrition, vol. 61, no. 4, pp. 443-460, 2007.

[6] W. Gunzer, M. Konrad, and E. Pail, "Exercise-induced immunodepression in endurance athletes and nutritional intervention with carbohydrate, protein and fat-what is possible, what is not?" Nutrients, vol. 4, no. 9, pp. 1187-1212, 2012.

[7] G. Davison, C. Kehaya, B. C. Diment, and N. P. Walsh, "Carbohydrate supplementation does not blunt the prolonged exercise-induced reduction of in vivo immunity," European Journal of Nutrition, vol. 55, no. 4, pp. 1583-1593, 2016.

[8] T. L. Sevier, "Infectious disease in athletes," Medical Clinics of North America, vol. 78, no. 2, pp. 389-412, 1994.

[9] J. P. R. Scott, C. Sale, J. P. Greeves, A. Casey, J. Dutton, and W. D. Fraser, "Effect of exercise intensity on the cytokine response to an acute bout of running," Medicine \& Science in Sports \& Exercise, vol. 43, no. 12, pp. 2297-2306, 2011.

[10] D. C. Nieman, M. Konrad, D. A. Henson, K. Kennerly, R. A. Shanely, and S. J. Wallner-Liebmann, "Variance in the acute inflammatory response to prolonged cycling is linked to exercise intensity," Journal of Interferon \& Cytokine Research, vol. 32, no. 1, pp. 12-17, 2012.

[11] R. C. Larrabee, "Leucocytosis after violent exercise," The Journal of Medical Research, vol. 7, no. 7, pp. 76-82, 1902.

[12] D. C. Nieman, "Current perspective on exercise immunology," Current Sports Medicine Reports, vol. 2, no. 5, pp. 239-242, 2003.

[13] A. Jeurissen, X. Bossuyt, J. L. Ceuppens et al., "The effects of physical exercise on the immune system," Nederlands Tijdschrift Voor Geneeskunde, vol. 147, no. 28, pp. 1347-1351, 2003.

[14] M. Ranieri, M. Megna, G. E. Lancioni et al., "Physical exercise and the immune system," International Journal of Immunopathology and Pharmacology, vol. 22, no. 3_suppl, pp. 29-32, 2009.

[15] M. D. Harris, "Infectious disease in athletes," Current Sports Medicine Reports, vol. 10, no. 2, pp. 84-89, 2011.

[16] F. C. Mooren, D. Blöming, A. Lechtermann, M. M. Lerch, and K. Völker, "Lymphocyte apoptosis after exhaustive and moderate exercise," Journal of Applied Physiology, vol. 93, no. 1, pp. 147-153, 2002.
[17] A. Eliakim, B. Falk, and B. Wollach, "Intense physical exercise--excessive strain on the immune system?" Harefuah, vol. 129, no. 11, pp. 498-502, 1995.

[18] D. C. Nieman, "Is infection risk linked to exercise workload?" Med Sci Sports Exerc, vol. 32, no. 7 Suppl, pp. S406-S411, 2000.

[19] D. C. Nieman, "Immune response to heavy exertion," Journal of Applied Physiology, vol. 82, no. 5, pp. 1385-1394, 1997.

[20] D. C. Nieman, "Risk of upper respiratory tract infection in athletes: an epidemiologic and immunologic perspective," Journal of Athletic Training, vol. 32, no. 32, pp. 344-349, 1997.

[21] R. Shephard and P. Shek, "Acute and chronic over-exertion: do depressed immune responses provide useful markers?" International Journal of Sports Medicine, vol. 19, no. 3, pp. 159-171, 1998.

[22] M. W. Kakanis, J. Peake, E. W. Brenu, M. Simmonds, B. Gray, and S. M. Marshall-Gradisnik, "T helper cell cytokine profiles after endurance exercise," Journal of Interferon \& Cytokine Research, vol. 34, no. 9, pp. 699-706, 2014.

[23] T.-C. Tuan, T.-G. Hsu, M.-C. Fong et al., "Deleterious effects of short-term, high-intensity exercise on immune function: evidence from leucocyte mitochondrial alterations and apoptosis," British Journal of Sports Medicine, vol. 42, no. 1, pp. 11-15, 2008.

[24] R. Albers, J.-M. Antoine, R. Bourdet-Sicard et al., "Markers to measure immunomodulation in human nutrition intervention studies," British Journal of Nutrition, vol. 94, no. 3, pp. 452-481, 2005.

[25] G. Broderick, M. A. Fletcher, M. Gallagher, Z. Barnes, S. D. Vernon, and N. G. Klimas, "Exploring the diagnostic potential of immune biomarker coexpression in Gulf War Illness," Methods in Molecular Biology, vol. 934, pp. 145-164, 2012.

[26] A. Di Meo, I. Batruch, A. G. Yousef, M. D. Pasic, E. P. Diamandis, and G. M. Yousef, "An integrated proteomic and peptidomic assessment of the normal human urinome," Clinical Chemistry and Laboratory Medicine (CCLM), vol. 55, no. 2, pp. 237-247, 2017.

[27] M. P. McTaggart, J. Lindsay, and E. M. Kearney, "Replacing urine protein electrophoresis with serum free light chain analysis as a first-line test for detecting plasma cell disorders offers increased diagnostic accuracy and potential health benefit to patients," American Journal of Clinical Pathology, vol. 140, no. 6, pp. 890-897, 2013.

[28] D. Samudrala, B. Geurts, P. A. Brown et al., "Changes in urine headspace composition as an effect of strenuous walking," Metabolomics, vol. 11, no. 6, pp. 1656-1666, 2015.

[29] Z. Chen and J. Kim, "Urinary proteomics and metabolomics studies to monitor bladder health and urological diseases," BMC Urology, vol. 16, no. 1, p. 11, 2016.

[30] M. Harpole, J. Davis, and V. Espina, "Current state of the art for enhancing urine biomarker discovery," Expert Review of Proteomics, vol. 13, no. 6, pp. 609-626, 2016.

[31] W. L. Zuo, R. H. Yu, J. Y. Zhang et al., "ITRAQ coupled with 2DLC-MS/MS to screen and identify speci-fic bio-markers of T-cell acute lymphoblastic leukemia," Zhongguo Shi Yan Xue Ye Xue Za Zhi, vol. 26, no. 1, pp. 77-82, 2018.

[32] C. Chen, T. Yan, L. Liu, J. Wang, and Q. Jin, "Identification of a novel serum biomarker for tuberculosis infection in Chinese HIV patients by iTRAQ-based quantitative proteomics," Frontiers in Microbiology, vol. 9, p. 330, 2018.

[33] C. Lin, W. C. Wu, G. C. Zhao et al., "ITRAQ-based quantitative proteomics reveals apolipoprotein A-I and transferrin as potential serum markers in CA19-9 negative pancreatic 
ductal adenocarcinoma," Medicine (Baltimore), vol. 95, no. 31, Article ID e4527, 2016.

[34] Y.-T. Chen, C.-L. Chen, H.-W. Chen et al., "Discovery of novel bladder cancer biomarkers by comparative urine proteomics using iTRAQ technology," Journal of Proteome Research, vol. 9, no. 11, pp. 5803-5815, 2010.

[35] Z. Guo, Y. Zhang, L. Zou et al., "A proteomic analysis of individual and gender variations in normal human urine and cerebrospinal fluid using iTRAQ quantification," PLoS One, vol. 10, no. 7, Article ID e0133270, 2015.

[36] M. Zhang, L. Chen, Z. Yuan et al., "Combined serum and EPSurine proteomic analysis using iTRAQ technology for discovery of potential prostate cancer biomarkers," Discovery Medicine, vol. 22, no. 122, pp. 281-295, 2016.

[37] J. Mu, Y. Yang, J. Chen et al., "Elevated host lipid metabolism revealed by iTRAQ-based quantitative proteomic analysis of cerebrospinal fluid of tuberculous meningitis patients," Biochemical and Biophysical Research Communications, vol. 466, no. 4, pp. 689-695, 2015.

[38] S. Srinivasan, M. Thangavelu, L. Zhang, K. B. Green, and K. K. Nichols, "iTRAQ quantitative proteomics in the analysis of tears in dry eye patients," Investigative Opthalmology \& Visual Science, vol. 53, no. 8, pp. 5052-5059, 2012.

[39] H.-c. Cho, J. Kim, S. Kim, Y. H. Son, N. Lee, and S. H. Jung, "The concentrations of serum, plasma and platelet BDNF are all increased by treadmill $\mathrm{VO}_{2}$ max performance in healthy college men," Neuroscience Letters, vol. 519, no. 1, pp. 78-83, 2012.

[40] H. Carter, J. S. Pringle, A. M. Jones, and J. H. Doust, "Oxygen uptake kinetics during treadmill running across exercise intensity domains," European Journal of Applied Physiology, vol. 86, no. 4, pp. 347-354, 2002.

[41] G. X. Wentao Lin and X. Weng, "The characteristic and mechanism of exercise-induced anemia during incremental intensity running," Journal of Beijing Sport University, vol. 34, no. 5, p. 4, 2011.

[42] F. Imeri, R. Herklotz, L. Risch et al., "Stability of hematological analytes depends on the hematology analyser used: a stability study with Bayer Advia 120, Beckman Coulter LH 750 and Sysmex XE 2100," Clinica Chimica Acta, vol. 397, no. 1-2, pp. 68-71, 2008.

[43] K. A. Reimann, M. R. G. O'Gorman, J. Spritzler et al., "Multisite comparison of CD4 and CD8 T-lymphocyte counting by single- versus multiple-platform methodologies: evaluation of beckman coulter flow-count fluorospheres and the tetraONE system," Clinical and Vaccine Immunology, vol. 7, no. 3, pp. 344-351, 2000.

[44] C. E. Thomas, W. Sexton, K. Benson, R. Sutphen, and J. Koomen, "Urine collection and processing for protein biomarker discovery and quantification," Cancer Epidemiology Biomarkers \& Prevention, vol. 19, no. 4, pp. 953-959, 2010.

[45] C. S. Gan, P. K. Chong, T. K. Pham, and P. C. Wright, "Technical, experimental, and biological variations in isobaric tags for relative and absolute quantitation (iTRAQ)," Journal of Proteome Research, vol. 6, no. 2, pp. 821-827, 2007.

[46] R. D. Unwin, J. R. Griffiths, and A. D. Whetton, "Simultaneous analysis of relative protein expression levels across multiple samples using iTRAQ isobaric tags with 2D nano LC-MS/MS," Nature Protocols, vol. 5, no. 9, pp. 1574-1582, 2010.

[47] R. Niu, Y. Liu, Y. Zhang et al., "iTRAQ-based proteomics reveals novel biomarkers for idiopathic pulmonary fibrosis," PLoS One, vol. 12, no. 1, Article ID e0170741, 2017.
[48] P. Minguez and P. Bork, "Bioinformatics analysis of functional associations of PTMs," Protein Bioinformatics, vol. 1558, pp. 303-320, 2017.

[49] A. Franceschini, D. Szklarczyk, S. Frankild et al., "STRING v9.1: protein-protein interaction networks, with increased coverage and integration," Nucleic Acids Research, vol. 41, no. D1, pp. D808-D815, 2013.

[50] D. Szklarczyk, A. Franceschini, S. Wyder et al., "STRING v10: protein-protein interaction networks, integrated over the tree of life," Nucleic Acids Research, vol. 43, no. D1, pp. D447D452, 2015.

[51] L. T. MacKinnon, "Special feature for the Olympics: effects of exercise on the immune system: overtraining effects on immunity and performance in athletes," Immunology and Cell Biology, vol. 78, no. 5, pp. 502-509, 2000.

[52] M. Gleeson, W. A. McDonald, A. W. Cripps, D. B. Pyne, R. L. Clancy, and P. A. Fricker, "The effect on immunity of long-term intensive training in elite swimmers," Clinical and Experimental Immunology, vol. 102, no. 102, pp. 210-216, 1995.

[53] L. T. Mackinnon and S. L. Hooper, "Plasma glutamine and upper respiratory tract infection during intensified training in swimmers," Medicine \& Science in Sports \& Exercise, vol. 28, no. 3, pp. 285-290, 1996.

[54] A. M. Novas, D. G. Rowbottom, and D. G. Jenkins, "Tennis, incidence of URTI and salivary IgA," International Journal of Sports Medicine, vol. 24, no. 3, pp. 223-229, 2003.

[55] G. Bellinghieri, V. Savica, and D. Santoro, "Renal alterations during exercise," Journal of Renal Nutrition, vol. 18, no. 1, pp. 158-164, 2008.

[56] A. Cantone and P. Cerretelli, "Effect of training on proteinuria following muscular exercise," Internationale Zeitschrift Für Angewandte Physiologie Einschliesslich Arbeitsphysiologie, vol. 18, no. 4, pp. 324-329, 1960.

[57] J. Poortmans, C. Geudvert, K. Schorokoff, and P. De Plaen, "Postexercise proteinuria in childhood and adolescence," International Journal of Sports Medicine, vol. 17, no. 6, pp. 448-451, 1996.

[58] J. R. Poortmans and J. Vanderstraeten, "Kidney function during exercise in healthy and diseased humans," Sports Medicine, vol. 18, no. 6, pp. 419-437, 1994.

[59] J. R. Poortmans, N. Mathieu, and P. De Plaen, "Influence of running different distances on renal glomerular and tubular impairment in humans," European Journal of Applied Physiology and Occupational Physiology, vol. 72, no. 5-6, pp. 522-527, 1996.

[60] A. Lundwall, A. Bjartell, A. Y. Olsson et al., "Semenogelin I and II, the predominant human seminal plasma proteins, are also expressed in non-genital tissues," Molecular Human Reproduction, vol. 8, no. 9, pp. 805-810, 2002.

[61] J. Klein, T. Papadopoulos, H. Mischak, and W. Mullen, "Comparison of CE-MS/MS and LC-MS/MS sequencing demonstrates significant complementarity in natural peptide identification in human urine," Electrophoresis, vol. 35, no. 7, pp. 1060-1064, 2014.

[62] I. Alvarez, J. A. Collado, R. Colobran et al., "Central T cell tolerance: identification of tissue-restricted autoantigens in the thymus HLA-DR peptidome," Journal of Autoimmunity, vol. 60 , pp. 12-19, 2015.

[63] Y. Zhang, Z. Wang, J. Zhang, and S. H. Lim, "Core promoter sequence of SEMG I spans between the two putative GATA-1 binding domains and is responsive to IL- 4 and IL-6 in myeloma cells," Leukemia Research, vol. 33, no. 1, pp. 166-169, 2009. 
[64] Y. Zhang, Z. Wang, J. Zhang, B. Farmer, and S. H. Lim, "Semenogelin I expression in myeloma cells can be upregulated pharmacologically," Leukemia Research, vol. 32, no. 12, pp. 1889-1894, 2008.

[65] O. G. de Jong, M. C. Verhaar, Y. Chen et al., "Cellular stress conditions are reflected in the protein and RNA content of endothelial cell-derived exosomes," Journal of Extracellular Vesicles, vol. 1, no. 1, Article ID 18396, 2012.

[66] M. Baldan-Martin, L. Mourino-Alvarez, L. Gonzalez-Calero et al., "Plasma molecular signatures in hypertensive patients with renin-angiotensin system suppression: new predictors of renal damage and de novo albuminuria Indicators," Hypertension, vol. 68, no. 1, pp. 157-166, 2016.

[67] L. Mirels, A. R. Hand, and H. J. Branin, "Expression of gross cystic disease fluid protein-15/prolactininducible protein in rat salivary glands," Journal of Histochemistry \& Cytochemistry, vol. 46, no. 9, pp. 1061-1071, 1998.

[68] W. W.-C. Chiu and L. W. Chamley, "Human seminal plasma prolactin-inducible protein is an immunoglobulin G-binding protein," Journal of Reproductive Immunology, vol. 60, no. 2, pp. 97-111, 2003.

[69] M. Autiero, G. Cammarota, A. Friedlein et al., "A 17-kDa CD4-binding glycoprotein present in human seminal plasma and in breast tumor cells," European Journal of Immunology, vol. 25, no. 5, pp. 1461-1464, 1995.

[70] M. Autiero, M. Gaubin, J.-C. Mani et al., "Surface plasmon resonance analysis of gp17, a natural CD4 ligand from human seminal plasma inhibiting human immunodeficiency virus type-1 gp120-mediated syncytium formation," European Journal of Biochemistry, vol. 245, no. 1, pp. 208-213, 1997.

[71] L. C. Schenkels, J. Schaller, E. Walgreen-Weterings, I. L. Schadee-Eestermans, E. C. Veerman, and A. V. Nieuw Amerongen, "Identity of human extra parotid glycoprotein (EP-GP) with secretory actin binding protein (SABP) and its biological properties," Biological Chemistry Hoppe-Seyler, vol. 375, no. 375, pp. 609-615, 1994.

[72] M. I. Hassan, A. Waheed, S. Yadav, T. P. Singh, and F. Ahmad, "Prolactin inducible protein in cancer, fertility and immunoregulation: structure, function and its clinical implications," Cellular and Molecular Life Sciences, vol. 66, no. 3, pp. 447-459, 2009.

[73] M. Gaubin, M. Autiero, S. Basmaciogullari et al., "Potent inhibition of CD4/TCR-mediated T cell apoptosis by a CD4binding glycoprotein secreted from breast tumor and seminal vesicle cells," Journal of immunology, vol. 162, no. 5, pp. 2631-2638, 1999.

[74] E. Caputo, M. Autiero, J.-C. Mani, S. Basmociogullari, D. Piatier-Tonneau, and J. Guardiola, "Differential antibody reactivity and $\mathrm{CD} 4$ binding of the mammary tumor marker protein GCDFP-15 from breast cyst and its counterparts from exocrine epithelia," International Journal of Cancer, vol. 78, no. 1, pp. 76-85, 1998.

[75] E. Caputo, V. Carratore, M. Ciullo et al., "Biosynthesis and immunobiochemical characterization of gp17/GCDFP-15. A glycoprotein from seminal vesicles and from breast tumors, in HeLa cells and in Pichia pastoris yeast," European Journal of Biochemistry, vol. 265, no. 2, pp. 664-670, 1999.

[76] J. Simard, A. C. Hatton, C. Labrief et al., "Inhibitory effect of estrogens on GCDFP-15 mRNA levels and secretion in ZR75-1 human breast cancer cells," Molecular Endocrinology, vol. 3, no. 4, pp. 694-702, 1989.

[77] J. Li, D. Liu, Z. Mou et al., "Deficiency of prolactin-inducible protein leads to impaired Th1 immune response and susceptibility to Leishmania major in mice," European Journal of Immunology, vol. 45, no. 4, pp. 1082-1091, 2015.

[78] K. Kawata, S. Kubota, T. Eguchi et al., "A tumor suppressor gene product, platelet-derived growth factor receptor-like protein controls chondrocyte proliferation and differentiation," Journal of Cellular Biochemistry, vol. 118, no. 11, pp. 4033-4044, 2017.

[79] P. M. Coan, O. Hummel, A. Garcia Diaz et al., "Genetic, physiological and comparative genomic studies of hypertension and insulin resistance in the spontaneously hypertensive rat," Disease Models \& Mechanisms, vol. 10, no. 3, pp. 297-306, 2017.

[80] S. Gross, K. Devraj, Y. Feng, J. Macas, S. Liebner, and T. Wieland, "Nucleoside diphosphate kinase B regulates angiogenic responses in the endothelium via caveolae formation and c-Src-mediated caveolin-1 phosphorylation," Journal of Cerebral Blood Flow \& Metabolism, vol. 37, no. 7, pp. 2471-2484, 2017.

[81] J. Teoh, S. Boulos, J. Chieng, N. W. Knuckey, and B. P. Meloni, "Erythropoietin increases neuronal NDPKA expression, and NDPKA up-regulation as well as exogenous application protects cortical neurons from in vitro ischemia-related insults," Cellular and Molecular Neurobiology, vol. 34, no. 3, pp. 379-392, 2014.

[82] R. Veluthakal, D. Kaetzel, and A. Kowluru, "Nm23-H1 regulates glucose-stimulated insulin secretion in pancreatic $\beta$-cells via Arf6-Rac1 signaling axis," Cellular Physiology and Biochemistry, vol. 32, no. 3, pp. 533-541, 2013.

[83] A. L. Bessa, V. N. Oliveira, G. Agostini et al., "Exercise intensity and recovery: biomarkers of injury, inflammation, and oxidative stress," Journal of Strength and Conditioning Research, vol. 30, no. 2, pp. 311-319, 2016.

[84] K. Sugama, K. Suzuki, K. Yoshitani et al., "Changes of thioredoxin, oxidative stress markers, inflammation and muscle/ renal damage following intensive endurance exercise," Exercise Immunology Review, vol. 21, no. 21, pp. 130-142, 2015.

[85] B. P. McDermott, C. R. Smith, C. L. Butts et al., "Renal stress and kidney injury biomarkers in response to endurance cycling in the heat with and without ibuprofen," Journal of Science and Medicine in Sport, vol. 21, no. 12, pp. 1180-1184, 2018.

[86] A. Del Rey and H. O. Besedovsky, "Immune-neuro-endocrine reflexes, circuits, and networks: physiologic and evolutionary implications," Endocrine Immunology, vol. 48, pp. 1-18, 2017.

[87] H. Moir, M. G. Hughes, S. Potter et al., "Exercise-induced immunosuppression: roles of reactive oxygen species and $5^{\prime}$ AMP-activated protein kinase dephosphorylation within immune cells," Journal of Applied Physiology, vol. 108, no. 5, pp. 1284-1292, 2010.

[88] C. C. W. G. Bongers, M. Alsady, T. Nijenhuis et al., "Impact of acute versus repetitive moderate intensity endurance exercise on kidney injury markers," Physiological Reports, vol. 5, no. 24, Article ID e13544, 2017. 